\title{
An In Vitro Comparison of the Bond Strength of Composite to Superficial and Deep Dentin, Treated With Er:YAG Laser Irradiation or Acid-Etching
}

\author{
Homayoon Alaghehmand1', Fatemeh Nezhad Nasrollah², Hanieh Nokhbatolfoghahaei ${ }^{3}$, Reza Fekrazad ${ }^{4,5^{*}}$ \\ 'Dental Materials Researches Center, Babol Medical Sciences University, Babol, Iran \\ ${ }^{2}$ Dental Material Research Center, Department of Restorative Dentistry, Faculty of Dentistry, Babol University of Medical \\ Sciences, Babol, Iran \\ ${ }^{3}$ School of Advanced Technologies in Medicine, Shahid Beheshti University of Medical Sciences, Tehran, Iran \\ ${ }^{4}$ Laser Research Center in Medical Sciences (LRCMS), Department of Periodontics, Faculty of Dentistry, AJA University of \\ Medical Sciences, Tehran, Iran \\ ${ }^{5}$ International Network for Photo Medicine and Photo Dynamic Therapy (INPMPDT), Universal Scientific Education and \\ Research Network (USERN), Tehran, Iran
}

\section{*Correspondence to \\ Reza Fekrazad, DDS, MSc; Laser Research Center in Medical Sciences (LRCMS), Department of Periodontics, Faculty of Dentistry, AJA University of Medical Sciences, International Network for Photo Medicine and Photo Dynamic Therapy (INPMPDT), Universal Scientific Education and Research Network (USERN), Tehran, Iran. Tel: +98-9123143138; \\ Fax: +98-88015017; \\ Email: rezafekrazad@gmail.com}

Published online 18 July 2016

\begin{abstract}
Introduction: The aim of this study was to compare the micro-shear bond strength of composite resin on superficial and deep dentin after conditioning with phosphoric acid and Erbium-Doped Yttrium Aluminum Garnet (Er:YAG) laser.

Methods: Thirty human molars were selected, roots were removed and crowns were bisected to provide a total of 60 half-crowns. Specimens were ground to expose superficial and deep dentin. Samples were assigned to six groups: (1) AS (acid etching of superficial dentin); (2) AD (acid etching of deep dentin); (3) LS (Er:YAG laser irradiation on superficial dentin); (4) LD (Er:YAG laser irradiation on deep dentin); (5) LAS (Er:YAG laser irradiation on superficial dentin followed by acid etching); (6) LAD (Er:YAG laser irradiation on deep dentin followed by acid etching) The adhesive protocol was performed. Samples were thermocycled and micro-shear bond strength was tested to failure. The data were submitted to statistical analysis with one-way analysis of variance (ANOVA) and Tukey post hoc test. Results: The AS group, demonstrated the greatest amount of micro-shear bond strength. Statistical analysis showed a decrease in bond strength in laser-treated groups which was more significant for deep dentin.

Conclusion: Preparation of dentin with laser did not improve bonding to superficial and deep dentin.

Keywords: acid-etch; composite; laser; micro-shear bond strength; bond strength.
\end{abstract}

\section{Introduction}

The last decade has been marked by a growing demand for aesthetic restorations and increasing priority of tooth structure preservation which have led to the development and improvement of adhesive materials. Micro-leakage at the tooth-restoration interface has been significantly reduced since the introduction of acid etching by Buonocore in $1955 .{ }^{1}$ The strength and durability of the bond between biomaterials and enamel/dentin are significant characteristics to be considered for mechanical, biological, and aesthetic purposes. Pulpal irritation and recurrent caries caused by micro-leakage can be eliminated by precise marginal adaptation of restorations. ${ }^{2}$ Extension of resin tags into the pores of the etched enamel surface provides micromechanical bonding. ${ }^{3}$ Resin bonding to dentin might lead to less desirable results in comparison to enamel. This might be due to the high organic content, presence of odontoblastic processes in dentinal tubules, smear layer, and surface moisture. ${ }^{4,5}$ Dentin surface treated with acid-etch undergoes physical and chemical alterations that allow for micromechanical and chemical bonding of adhesive materials. ${ }^{6}$ The bonding process occurs most efficiently when resin monomers impregnated into partially demineralized dentin create a dentin-resin inter-diffusion zone. This process is highly dependent on the microstructure of the dentin, composed of fluid-filled dentin tubules surrounded by a peri-tubular zone and an inter-tubular matrix. ${ }^{7}$ This structure differs noticeably between superficial and deep dentin with regard to the number of tubules and the amount of peri-tubular and inter-tubular zones. Accordingly, each type of dentin presents different characteristics and requirements for resin

Please cite this article as follows: Alaghehmand $\mathrm{H}$, Nezhad Nasrollah F, Nokhbatolfoghahaei H, Fekrazad R. An in vitro comparison of the bond strength of composite to superficial and deep dentin, treated with Er:YAG laser irradiation or acid-etching. J Lasers Med Sci. 2016;7(3):167-171. doi:10.15171/jlms.2016.29. 
bonding. ${ }^{4,7,8}$

In search for more advantageous tooth surface conditioning techniques to replace acid-etching, recent investigations have focused on laser application. ${ }^{9,10}$ During laser treatment, light is converted into heat, which causes ablation and dentin etching. Lasers have been employed for tooth surface modification and improving restoration bonding. ${ }^{11-14}$ Erbium-Doped Yttrium Aluminum Garnet (Er:YAG) laser has the capacity to produce a micro-retentive pattern when applied on tooth surfaces. The effect of Er:YAG laser depends on parameters such as energy output, frequency, pulse mode, and irradiation time. The safety and efficacy of application of Er:YAG laser on dental tissues has been approved. The literature available on Er:YAG laser presents varying parameters and results, yet it lacks a clarified conclusion on the actual efficacy of this technique on improving resin adhesion, particularly on deep dentin. The present study aimed to compare the effectiveness of Er:YAG laser for etching superficial and deep dentin for bonding of a composite resin material with that of acid-etching.

\section{Methods}

Specimen Preparation

This study was performed using 30 extracted intact human third molars. The teeth, all extracted within a duration of 6 months, were kept in $0.9 \%$ sodium chloride solution until the beginning of the experiment. The teeth were cleaned with non-fluoridated pumice and dental prophylactic cups. Roots were sectioned at $2 \mathrm{~mm}$ below the cementoenamel junction, and the remaining crowns were randomly divided into two groups and inserted into an epoxy resin block, with the upper portion of the crowns left unembedded. The teeth were inserted in a position parallel to the sides of the block. Each tooth should provide both superficial and deep dentin so a sectioning machine (Non Stop, Germany) was used to cut the crowns in half in a mesiodistal direction, providing a total of 60 half-crowns. The cutting process proceeded at low speed with refrigeration. In 30 of the half-crowns, superficial dentin was exposed within a $0.5-\mathrm{mm}$ distance from the enamel at the central occlusal groove. In the remaining 30 specimens, deep dentin was exposed at a $0.5-\mathrm{mm}$ distance from the highest pulp horn. Subsequently, the specimens were randomly allocated into six groups (each containing 10 specimens): group 1- AS (acid etching of superficial dentin); group 2- AD (acid etching of deep dentin); group 3- LS (Er:YAG laser irradiation on superficial dentin); group 4- LD (Er:YAG laser irradiation on deep dentin); group 5- LAS (Er:YAG laser irradiation on superficial dentin followed by acid etching); group 6- LAD (Er:YAG laser irradiation on deep dentin followed by acid etching).

\section{Surface Treatment}

Dentin surfaces treatment with acid etching in groups 1 and 2 included conditioning the surface by $37 \%$ phosphoric acid gel (3M-ESPE, St. Paul, MN, USA) for $15 \mathrm{sec}-$ onds followed by thorough water rinsing and air drying.
In group 2 to 6, surface treatment was performed with an Er:YAG laser machine (Dr Smile, Italy). According to the manufacturer's instructions, laser irradiation was oriented perpendicular to the surface. Focal distance was 10 $\mathrm{mm}$ and laser beam spot size was $0.63 \mathrm{~mm}$. With an energy of $80 \mathrm{~mJ}$ and a frequency of $2 \mathrm{~Hz}$, laser scanning was performed for 20 seconds with $5 \mathrm{~mL} / \mathrm{min}$ water irrigation. In groups 5 and 6 , laser irradiation was followed by acid etching in a similar procedure as mentioned above.

Following surface treatment, a uniform layer of adhesive (single bond 2, 3M-ESPE, St. Paul, MN, USA) was applied on the dentin surfaces using disposable brush tips and following the manufacturer's instructions. After gentle air-drying the specimens for $5 \mathrm{~s}$, adhesive materials were polymerized for 20 seconds using a light-curing unit (XL 3000, 3M Dental Products, USA). The output of the light curing device was measured with a radiometer (Demetron/Kerr, Danbury, CT, USA) which showed 450 $\mathrm{mW} / \mathrm{cm}^{2}$.

From each group, 1 sample was randomly selected to be analyzed with scanning electron microscopy. The rest of the samples received composite resin materials (z250 $3 \mathrm{M}$ - ESPE, St. Paul, MN, USA) on the prepared dentin surfaces. All prepared dentin surfaces in all groups were completely covered by composite. Composite resin material was manually applied and Light-cured by a visible-light-curing unit (XL 3000, 3M Dental Products, USA) for 60 seconds.

The samples were stored in a physiological solution at body temperature. After 7 days, all samples were subjected to 500 rounds of thermal cycling, each consisting of 20 seconds in water bath at $5{ }^{\circ} \mathrm{C}$ and $55^{\circ} \mathrm{C}$, with an exchange time of $10 \mathrm{~s}$ between the baths. Subsequently, specimens were sectioned vertically using the sectioning machine (Non Stop, Germany), to provide 36 dentin-composite rectangular slabs with a cross-section of $1 * 1 \mathrm{~mm}^{2} .{ }^{15}$

\section{Bond Strength Testing}

The micro-shear bond strength of the samples was tested on a micro-tensile tester machine (COMPACT GAUGE $200 \mathrm{~N}$, Bisco. Inc). The samples in acrylic resin cylinders were protected on the platform, so as the axis of the composite slab perpendicular to the direction of the crosshead travel. The crosshead speed was $0.5 \mathrm{~mm} / \mathrm{s}$. The force at which the composite was dislodged from the dentine surface was recorded in $\mathrm{N}$, and the shear bond strength was measured from the cross-sectional area of the composite. The averages and standard deviations were calculated and the data were submitted to statistical analysis by one-way analysis of variance (ANOVA) and Tukey post hoc test.

\section{Results}

The average bond strengths in superficial dentin were AS: $5.33 \pm 2.15$, LS: $2.95 \pm 0.66$, LAS: $4.97 \pm 1.34(\mathrm{P}<0.001)$

The statistical analysis revealed that there was no statistically significant difference between the groups AS and LAS; however, the group LS showed significantly lower 


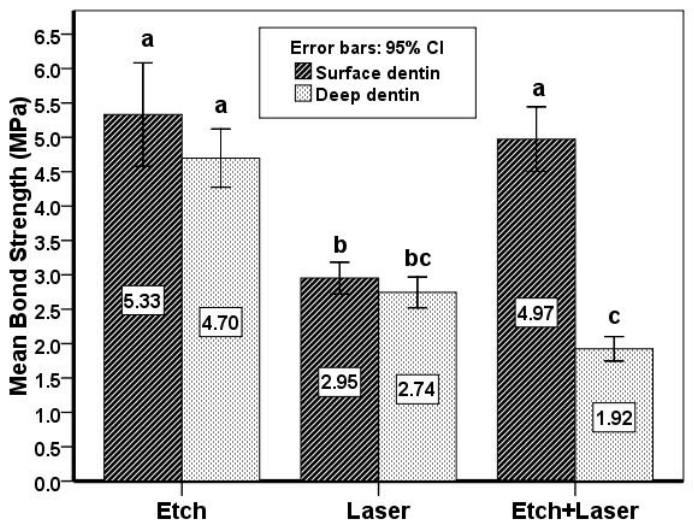

Figure 1. The Average Bond Strength Measured in the 6 Experimental Groups (small letters show significant difference between the groups $-P<0.001$ )

bond strength (Figure 1). The average bond strengths in deep dentin were $\mathrm{AD}: 4.70 \pm 1.21$, LD: $2.74 \pm 0.64$, LAD: $1.92 \pm 0.5(P<0.001)$. There was no statistically significant difference between the LD and LAD groups, however, the ED group showed a significantly higher bond strength (Figure 1).

No significant differences were found for Er:YAG laser-irradiation or phosphoric acid etching between superficial and deep dentin. The combination of phosphoric acid etching and Er:YAG laser irradiation improved the micro-shear bond Strength of composite resin on superficial dentin as compared to Er:YAG laser $(P<0.05)$

The dentin tubules were shown to be exposed in SEM photographs of the superficial and deep dentin surfaces (Figure 2A-F).

\section{Discussion}

This study was conducted to compare Er:YAG laser irradiation and acid-etching for treatment of superficial and deep dentin surfaces prior to the application of adhesive materials. Chemical changes as well as surface roughening induced in dentin by laser irradiation might increase the bonding surface area, hence the adhesion. . 14,16,17 $^{-1}$

The recent literature has not precisely verified the superiority of laser irradiation to acid-etching for treating dentinal surfaces prior to bonding. ${ }^{18-32}$ Previous reports have claimed that there are certain advantages in bonding to lased dentin because of an apparently enlarged surface area for adhesion based on the scaly and flaky surface appearance following Er:YAG irradiation. ${ }^{33-35}$ In a study, the shear bond strength in deep lased dentin was better than in superficial lased dentin. ${ }^{36}$ In addition, acid etching the previously laser-conditioned dentin surfaces has proved to be an effective technique. It was therefore concluded that the surface modification caused by Er:YAG laser does not improve the adhesion of bonding materials to dentin and cannot replace the conventional acid etching technique. ${ }^{23}$ Er:YAG laser diminishes the water content as well as the organic tissue of dentin at sub-ablative energy densities. ${ }^{37}$ Moreover, subsurface fissuring in dentin following treatment with Er:YAG laser can be detrimental to the adhesion. ${ }^{19}$ Laser-induced subsurface damage to dentin has been demonstrated by cracks created under the hybrid layer. Fe-SEM examination has demonstrated the presence of micro-cracks to be more abundant in laser-irradiated dentin surfaces than in fractured dentin surfaces. $^{38}$

Dentin surface modifications made by laser irradiation, even if further altered by acid-etching, might not allow for proper adhesion of bonding resins, since laser irradiation provides an acid-resistant surface. On the other hand, as the hybridization is an imperative for adhesion of dentin bonding materials, removal of organic tissue by laser impedes this process. In addition, the previously mentioned subsurface damage might extend beyond the hybrid layer.
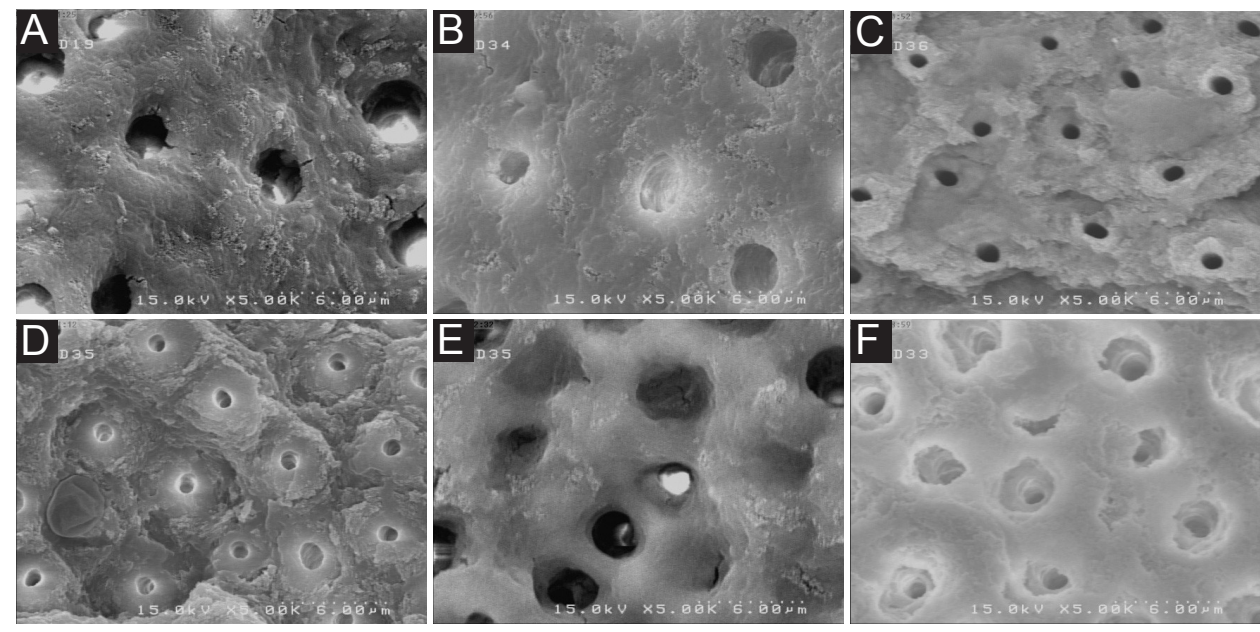

Figure 2. Scanning electron microscopic photograph of acid etched superficial dentin (original magnification $\times 5000$ ). (B) Scanning electron microscopic photograph of acid etched deep dentin (original magnification $\times 5000$ ). (C) Scanning electron microscopic photograph of laser-treated superficial dentin (original magnification $\times 5000$ ). (D) Scanning electron microscopic photograph of laser-treated deep dentin (original magnification $\times 5000$ ). (E) Scanning electron microscopic photograph of laser-treated and acid-etched superficial dentin (original magnification $\times 5000$ ). $(F)$ Scanning electron microscopic photograph of laser-treated and acid-etched deep dentin (original magnification $\times 5000)$ 
This condition weakens the substrate and causes cohesive dentin fracture. ${ }^{18,19,22,38}$ The potential role of subsurface damage and the limited hybridization in low tensile bone strength has been confirmed in laser-treated cavities; the superficial layer was removed by acid-etching or air abrasion. ${ }^{21,24}$ Laser irradiation seems not to be able to create an inter-diffusion zone similar to that created by acid etching. ${ }^{37,39,40}$

It is worth mentioning that verification, i.e. recrystallization of dentin apatite and formation of more calcium phosphate, has not been evaluated thoroughly. Thanks to verification, acid-resistance, dental hardness and abrasion are increased. Dentinal permeability might also be reduced as a result of sealing the dentinal tubules up to a considerable depth. ${ }^{41-43}$ Such alterations in dentinal surfaces might impede the proper bonding of restorative materials and cause cohesive micro-fractures. ${ }^{19}$

\section{Conclusion}

Within the limitations of this in vitro study, it may be concluded that laser treatment of dentinal surfaces negatively affects the bond strength when compared to acid etching. Contradictions still remains regarding the most effective way of accomplishing adhesion on Er:YAG laser-irradiated surfaces. This controversy might be partly due to the heterogeneity of methods for dentin conditioning with laser. Accordingly, it might be suggested that a standard energy output be defined for treatment of different dental tissues. Further research is required to precisely determine the effect of laser conditioning on adhesion of bonding materials to dentinal surfaces.

\section{Conflict of Interests}

The authors declare that there is no conflict of interest regarding the publication of this paper.

\section{References}

1. Buonocore MG. A simple method of increasing the adhesion of acrylic filling materials to enamel surfaces. $J$ Dent Res. 1955;34(6):849-853. doi:10.1177/002203455503 40060801.

2. Nakabayashi N. Adhesive bonding with 4-META. Oper Dent Suppl. 1992;5:125-130.

3. Wang WN, Meng CL. A study of bond strength between light- and self-cured orthodontic resin. Am J Orthod Dentofacial Orthop. 1992;101(4):350-354. doi:10.1016/ s0889-5406(05)80328-2.

4. Pashley DH. Dentin: a dynamic substrate--a review. Scanning Microsc. 1989; 3(1):161-74.

5. Soderholm KJ. Correlation of in vivo and in vitro performance of adhesive restorative materials: a report of the ASC MD156 Task Group on Test Methods for the Adhesion of Restorative Materials. Dent Mater. 1991;7(2):74-83. doi:10.1016/0109-5641(91)90049-5.

6. Erickson RL. Surface interactions of dentin adhesive materials. Oper Dent. 1992;Suppl 5:81-94.

7. Marshall GW Jr, Marshall SJ, Kinney JH, Balooch M. The dentin substrate: structure and properties related to bonding. J Dent. 1997;25(6):441-58.

8. Marshall GW Jr. Dentin: microstructure and characterization. Quintessence Int. 1993;24(9):606-617.

9. Featherstone JD, Nelson DG. Laser effects on dental hard tissues. Adv Dent Res. 1987;1(1):21-26.

10. Nelson DG, Wefel JS, Jongebloed WL, Featherstone JD. Morphology, histology and crystallography of human dental enamel treated with pulsed low-energy infrared laser radiation. Caries Res. 1987; 21(5):411-426. doi:10.1002/ lsm.1900040404.

11. Liberman R, Segal TH, Nordenberg D, Serebro LI. Adhesion of composite materials to enamel: comparison between the use of acid and lasing as pretreatment. Lasers Surg Med. 1984;4(4):323-327. doi:10.1002/lsm.1900040404

12. Cooper LF, Myers ML, Nelson DG, Mowery AS. Shear strength of composite bonded to laser-pretreated dentin. J Prosthet Dent. 1988;60(1):45-49. doi:10.1016/00223913(88)90348-4.

13. Walsh LJ, Abood D, Brockhurst PJ. Bonding of resin composite to carbon dioxide laser-modified human enamel. Dent Mater. 1994;10(3):162-166. doi:10.1016/01095641(94)90026-4.

14. Visuri SR, Gilbert JL, Wright DD, Wigdor HA, Walsh JT, Jr. Shear strength of composite bonded to Er:YAG laserprepared dentin. J Dent Res. 1996; 75(1):599-605.

15. de Souza AE, Corona SA, Dibb RG, Borsatto MC, Pecora JD. Influence of Er:YAG laser on tensile bond strength of a self-etching system and a flowable resin in different dentin depths. J Dent. 2004; 32(4):269-75.

16. Keller U, Hibst R. Effects of Er:YAG laser in caries treatment: a clinical pilot study. Lasers Surg Med. 1997;20(1):32-8.

17. Patel BC, Rickwood KR. Morphological changes induced by short pulse hydrogen fluoride laser radiation on dental hard tissue and restorative materials. Lasers Surg Med. 1997; 21(1):1-6.

18. Kameyama A, Kawada E, Takizawa M, Oda Y, Hirai Y. Influence of different acid conditioners on the tensile bond strength of 4-META/MMA-TBB resin to Er:YAG laserirradiated bovine dentin. J Adhes Dent. 2000;2(4):297-304.

19. Martinez-Insua A, Da Silva Dominguez L, Rivera FG, Santana-Penin UA. Differences in bonding to acidetched or Er:YAG-laser-treated enamel and dentin surfaces. J Prosthet Dent. 2000; 84(3):280-8. doi:10.1067/ mpr.2000.108600.

20. Burnett LH Jr, Conceicao EN, Pelinos JE, Eduardo CD. Comparative study of influence on tensile bond strength of a composite to dentin using Er:YAG laser, air abrasion, or air turbine for preparation of cavities. J Clin Laser Med Surg. 2001;19(4):199-202. doi:10.1089/104454701316918970.

21. Eguro $T$, Maeda $T$, Tanabe $M$, Otsuki M, Tanaka $H$. Adhesion of composite resins to enamel irradiated by the Er:YAG laser: application of the ultrasonic scaler on irradiated surface. Lasers Surg Med. 2001;28(4):365-370.

22. Kameyama A, Oda Y, Hirai Y, Kawada E, Takizawa M. Resin bonding to Er: YAG laser-irradiated dentin: combined effects of pre-treatments with citric acid and glutaraldehyde. Eur J Oral Sci. 2001;109(5):354-360. doi:10.1034/j.1600-0722.2001.00075.x.

23. Ceballo L, Toledano M, Osorio R, Tay FR, Marshall GW. Bonding to Er-YAG-laser-treated dentin. J Dent Res. 2002;81(2):119-122. doi:10.1177/154405910208100207.

24. Eguro T, Maeda T, Otsuki M, Nishimura Y, Katsuumi I, Tanaka H. Adhesion of Er:YAG laser-irradiated dentin and composite resins: application of various treatments on irradiated surface. Lasers Surg Med. 2002;30(4):267-72. 
doi:10.1002/lsm.10043.

25. Goncalves M, Corona SA, Borsatto MC, Silva PC, Pecora JD. Tensile bond strength of dentin-resinous system interfaces conditioned with Er:YAG laser irradiation. J Clin Laser Med Surg. 2002;20(2):89-93. doi:10.1089/104454702753768070.

26. Ramos RP, Chimello DT, Chinelatti MA, Nonaka T, Pecora JD, Palma Dibb RG. Effect of Er:YAG laser on bond strength to dentin of a self-etching primer and two singlebottle adhesive systems. Lasers Surg Med. 2002;31(3):164170. doi:10.1002/lsm.10106.

27. Otsuki M, Eguro T, Maeda T, Tanaka H. Comparison of the bond strength of composite resin to Er:YAG laser irradiated human enamel pre-treated with various methods in vitro. Lasers Surg Med. 2002; 30(5):351-359. doi:10.1002/ lsm.10049.

28. Goncalves M, Corona SA, Pecora JD, Dibb RG. Influence of the frequency of Er:YAG laser on the bond strength of dental enamel. J Clin Laser Med Surg. 2003; 21(2):105-108.

29. Trajtenberg CP, Pereira PN, Powers JM. Resin bond strength and micromorphology of human teeth prepared with an Erbium:YAG laser. Am J Dent. 2004; 17(5):331-336.

30. Chimello-Sousa DT, de Souza AE, Chinelatti MA, Pecora JD, Palma-Dibb RG, Milori Corona SA. Influence of Er:YAG laser irradiation distance on the bond strength of a restorative system to enamel. J Dent. 2006;34(3):245-251.

31. Dunn WJ, Davis JT, Bush AC. Shear bond strength and SEM evaluation of composite bonded to Er:YAG laserprepared dentin and enamel. Dent Mater. 2005;21(7):616224.

32. Oliveira DC, Manhaes LA, Marques MM, Matos AB. Microtensile bond strength analysis of different adhesive systems and dentin prepared with high-speed and Er:YAG laser: a comparative study. Photomed Laser Surg. 2005;23(2):219-24.

33. KellerU, Hibst R. Experimental studies of the Er:Yag laser on dental hard substances II. Light microscopic and SEM investigations. Laser Surg Med. 1989;9:345-351.

34. Visuri s, Gilbert J, Wrigdor H, Walsh JJ. Shear strength of composite bonded to Er:YAG laser -prepared dentin. J
Dent Res. 1996;75:599-605.

35. Stiesch-Scholz M, Hanning M. In vitro study of enamel and dentin marginal integrity of composite and compomer restorations placed in primary teeth after diamond or Er:YAG laser cavity preparation . J Adhes Dent. 2000;2:213222.

36. Koliniotou-Koumpia E, Kouros P, Zafiriadis L, Koumpia E, Dionysopoulos P, Karagiannis V. Bonding of adhesives to Er:YAG laser-treated dentin. Eur J Dent. 2012;6(1):16-23.

37. Bachmann L, Diebolder R, Hibst R, Zezell DM. Changes in chemical composition and collagen structure of dentine tissue after erbium laser irradiation. Spectrochim Acta A Mol Biomol Spectrosc. 2005; 61(11-12):2634-2639. doi:10.1016/j.saa.2004.09.026.

38. De Munck J, Van Meerbeek B, Yudhira R, Lambrechts P, Vanherle G. Micro-tensile bond strength of two adhesives to Erbium:YAG-lased vs. bur-cut enamel and dentin. Eur J Oral Sci. 2002;110(4):322-329. doi:10.1034/j.16000722.2002.21281.x.

39. Schein MT, Bocangel JS, Nogueira GE, Schein PA. SEM evaluation of the interaction pattern between dentin and resin after cavity preparation using ER:YAG laser. J Dent. 2003;31(2):127-135. doi:10.1016/s0300-5712(03)00003-4.

40. Bertrand MF, Hessleyer D, Muller-Bolla M, Nammour S, Rocca JP. Scanning electron microscopic evaluation of resin-dentin interface after Er:YAG laser preparation. Lasers Surg Med. 2004;35(1):51-57. doi:10.1002/lsm.20063.

41. Sassi JF, Chimello DT, Borsatto MC, Corona SA, Pecora JD, Palma-Dibb RG. Comparative study of the dentin/adhesive systems interface after treatment with Er:YAG laser and acid etching using scanning electron microscope. Lasers Surg Med. 2004;34(5):385-390. doi:10.1002/lsm.20064.

42. Fowler BO, Kuroda S. Changes in heated and in laserirradiated human tooth enamel and their probable effects on solubility. Calcif Tissue Int. 1986; 38(4):197-208. doi:10.1007/bf02556711.

43. Oho T, Morioka T. A possible mechanism of acquired acid resistance of human dental enamel by laser irradiation. Caries Res. 1990; 24(2):86-92. doi:10.1159/000261245 